\title{
ANALISIS SWOT PENGEMBANGAN EKONOMI KHUSUS INDUSTRI NIKEL DI PROVINSI SULAWESI TENGGARA
}

\author{
SWOT Analysis of Exclusive Economic Development of Nickel \\ Industry in Southeast Sulawesi Province
}

\author{
MEITHA SUCIYANTI dan HARTA HARYADI \\ Puslitbang Teknologi Mineral dan Batubara \\ Jalan Jenderal Sudirman 623 Bandung 40211 \\ Telp. (022) 6030483, Fax. (022) 6003373 \\ e-mail: meitha@tekmira.esdm.go.id
}

\begin{abstract}
ABSTRAK
Indonesia memiliki sumber daya nikel yang besar dengan jumlah 5.756 .362 .683 ton, sebagian besar berada di Sulawesi Tenggara, Sulawesi Tengah, Sulawesi Selatan, Maluku Utara, Papua dan sebagian kecil di Papua Barat serta Kalimantan Timur. Langkah pemerintah melarang ekspor bijih nikel tanpa melalui pengolahan dan pemurnian sebagai amanat Undang-Undang Nomor 4 Tahun 2009, mendorong pemerintah untuk menyediakan kawasan ekonomi khusus untuk membangun pabrik pengolahan dan pemurnian nikel. Tujuan kajian ini adalah tersusunnya rumusan strategi sebagai masukan untuk menentukan Kawasan Eknomi Khusus di Sulawesi Tenggara. Metodologi analisisnya menggunakan analisis strength, weakness, opportunities and threat. Hasil analisis menunjukkan, kawasan ini cocok dibangun di provinsi ini. Strategi yang harus diambil pemerintah provinsi adalah mendayagunakan sumber daya manusia yang berkualitas dan profesional serta penggunaan teknologi modern untuk memanfaatkan sumber daya dan cadangan nikel yang dimilikinya untuk mengantisipasi ancaman kekurangan input bahan baku akibat provinsi lainnya tidak mau memasoknya. Di samping itu harus memperbaiki infrastruktur, mengatasi kekurangan energi untuk menghasilkan produk yang bernilai tinggi dalam rangka meraih peluang pasar ekspor yang besar dan untuk memasok bahan baku industri dalam negeri. Hasil analisis ini dapat dijadikan bahan masukan rumusan kebijakan bagi pemerintah dalam upaya menentukan Kawasan Ekonomi Khusus pabrik pengolahan dan pemurnian nikel di Sulawesi Tenggara.
\end{abstract}

Kata kunci: kekuatan-kelemahan-peluang-ancaman, kawasan ekonomi khusus, pengolahan dan pemurnian nikel, Sulawesi Tenggara

\begin{abstract}
Indonesia has large nickel resources, totaled 5,756,362,683 tons, which are mostly located in Southeast Sulawesi, Central Sulawesi, South Sulawesi, North Moluccas, Papua and a small portion in West Papua and East Kalimantan. The government measures prohibiting the export of nickel ore without processing and purification as a mandate of Law Number 4/ 2009 and urge the government to provide exclusive economic zones to build nickel smelters. The objective of the study is to formulate the strategy as an input to determine an exclusive economic zone in Southeast Sulawesi. Methodology of the study uses an analysis of strength, weakness, opportunity and threat. The results of the analysis show that the zone is suitable to be built in Southeast Sulawesi and the strategy to be taken by the government of Southeast Sulawesi Province is to utilize qualified and professional human resources and the use of modern technology to utilize its resources and nickel reserves
\end{abstract}


to anticipate the threat of material input shortage, improvement of infrastructure, overcome the energy shortages to produce high-value products in order to grab large export market opportunities and to supply domestic industrial raw materials. The results of the analysis can be used as an input of policy formulation for the government in the effort to determine the exclusive economic zone of nickel smelter in Southeast Sulawesi.

Keywords: strength-weakness-opportunity-threats, exclusive economic zones, processing and purification of nickel, Southeast Sulawesi

\section{PENDAHULUAN}

Indonesia memiliki sumber daya mineral logam yang sangat besar, dan salah satunya adalah nikel sebesar 5.756.362.683 ton (Pusat Sumber Daya Geologi, 2016) yang tersebar di beberapa provinsi. Sumber daya mineral ini belum memberikan manfaat ekonomi yang signifikan, karena sebagian besar diekspor dalam bentuk mentah, harganya murah dan nilai perolehan ekonominya rendah, sehingga Indonesia kehilangan nilai tambah yang tinggi. Namun di sisi lain dalam jangka pendek, kebijakan pengolahan barang ekspor ini akan memberikan dampak berkurangnya nilai ekspor dan dampak ketenagakerjaan (Yunianto, 2014).

Sesuai amanat Undang Undang Republik Indonesia Nomor 4 Tahun 2009 (UU 4/2009) tentang Pertambangan Mineral dan Batubara, pemegang Izin Usaha Pertambangan dan Izin Usaha Pertambangan Khusus wajib melakukan pengolahan dan pemurnian bijih nikel di dalam negeri sebelum diekspor menjadi barang setengah jadi (konsentrat) atau barang yang sudah jadi (logam). Langkah yang diambil pemerintah untuk menghentikan ekspor bijih nikel tanpa melalui proses pengolahan dan pemurnian (Permana, 2010), bertujuan untuk meningkatkan nilai tambah bijih nikel, baik nilai ekonomi maupun daya gunanya, peningkatan ekonomi wilayah pemilik sumber daya nikel (Produk Domestik Regional Bruto), peningkatan ekonomi nasional (Produk Domestik Bruto), peningkatan kesempatan kerja bagi tenaga kerja yang profesional, sebagai pemenuhan bahan baku untuk industri hilir di dalam negeri yang selama ini dipasok impor, hasil produknya memiliki daya saing yang tinggi di pasar ekspor dan bisa menguasai pasar. Selain itu, usaha peningkatan nilai tambah (PNT) ini akan memberikan dampak efek pengganda yang positif terhadap perokonomian dan sosial, baik bagi daerah operasional tambang, maupun daerah nonoperasional dalam satu wilayah provinsi, dan dampak positif secara nasional (Haryadi, 2016).

Substansi UU 4/2009 menegaskan bahwa para pengusaha pemegang IUP dan IUPK nikel wajib membangun pabrik pengolahan dan pemurnian bijih nikel di dalam negeri dan pemerintah didorong untuk menyediakan lokasi khusus atau Kawasan Ekonomi Khusus (KEK) untuk pabrik tersebut. Agar KEK pabrik tersebut dapat terwujud, maka harus memenuhi syarat dan mendukung dari segala aspek, sehingga pabrik ini bisa berdiri dengan sukses (Badan Perencanaan Nasional, 2016), antara lain pasokan bahan baku yang cukup besar yang mampu memasok bahan baku minimal 25 tahun agar menguntungkan bagi perusahaan, peningkatan kemampuan teknologi, melakukan inovasi, dukungan lembaga keuangan, perbaikan infrastruktur dan logistik, pembangunan industri pendukung, peningkatan mesin pengolahan bahan baku, dukungan energi, ketersediaan informasi dan kebijakan ekspor produk yang bernilai tambah. Di sisi lain, pembangunan pabrik pengolahan dan pemurnian mineral (smelter) yang diwajibkan kepada seluruh pengusaha sektor pertambangan (pemegang IUP) saat ini terkendala dengan minimnya infrastruktur, ketersediaan energi listrik, serta sumber daya manusia. Namun, ketiga hal ini dapat diatasi dengan adanya investasi yang masuk ke dalam negeri (Damuri, Christian dan Atje, 2015).

Pembangunan KEK pabrik pengolahan dan pemurnian nikel direncanakan di Provinsi Sulawesi Tenggara, yakni di Kecamatan Bondoiala dan Kapoiala, Kabupaten Konawe dengan luas lahan sekitar 5.500 hektar. Kegiatan utama dalam KEK meliputi industri terpadu pabrik feronikel dan industri baja dan produk hilirnya. Pembangunan KEK didasarkan atas potensi sumber daya dan cadangan nikel yang dimiliki kabupaten ini.

Sulawesi Tenggara merupakan salah satu provinsi yang masuk ke dalam koridor 4, yaitu 
Koridor Ekonomi Sulawesi-Maluku Utara dalam kerangka Masterplan Percepatan dan Perluasan Pembangunan Ekonomi Indonesia, yang dituangkan ke dalam Perpres Nomor 32 Tahun 2011 Tentang Masterplan Percepatan dan Perluasan Pembangunan Ekonomi Indonesia (MP3El) 2011-2025, diarahkan untuk menjadi kawasan pusat industri pertambangan nasional mengingat wilayah ini memiliki berbagai sumber daya mineral dan energi yang cukup beragam, memiliki potensi cadangan yang cukup besar dan memiliki nilai ekonomi yang cukup tinggi (Wahyuni dan Wahyuningsih, 2016).

Untuk menentukan KEK pabrik pengolahan dan pemurnian nikel di Provinsi Sulawesi Tenggara, dibanding provinsi lain yang memiliki sumber daya nikel yang besar seperti Sulawesi Tengah, Sulawesi Selatan, Maluku Utara, Papua, Papua Barat dan Kalimantan Timur, dilakukan analisis strength (kekuatan), weakness (kelemahan), opportunity (peluang) and threat (ancaman) (SWOT). Analisis ini adalah sebuah metode untuk mengetahui lingkungan internal yang dimiliki Provinsi Sulawesi Tenggara (Arminsyurita, 2014).

Metode analisis SWOT terhadap penentuan KEK ini, merupakan metode analisis yang paling dasar, yang berguna untuk melihat suatu topik atau permasalahan dari 4 sisi yang berbeda (Amalia, 2016). Hasil analisis SWOT adalah rekomendasi dalam merumuskan rencana strategis Provinsi Sulawesi Tenggara yang terpilih menjadi KEK untuk pabrik pengolahan dan pemurnian nikel dalam rangka mempertahankan kekuatan dan meraih peluang yang ada, sambil mengurangi kekurangan dan menghindari ancaman (Erlina, 2009).

Tujuan analisis ini adalah tersusunnya rumusan strategi sebagai masukan untuk menentukan KEK pabrik pengolahan dan pemurnian nikel di Sulawesi Tenggara.

\section{METODE}

Dalam analisis ini, untuk mendapatkan data primer, digunakan metode observasi dan wawancara dengan Dinas Energi dan Sumber Daya Mineral Provinsi Sulawesi Tenggara, Maluku Utara, Papua dan beberapa perusahaan tambang. Data sekunder diperoleh melalui studi literatur dari berbagai jurnal, prosiding, skripsi, makalah dari Direktorat Jenderal Mineral dan Batubara, Pusat Sumber daya Geologi, Badan Pusat Statistik dan instansi terkait lainnya. Dari hasil observasi dan wawancara dapat diketahui faktor strategis internal (kekuatan dan kelemahan) dan faktorfaktor strategis eksternal (peluang dan ancaman). Dari hasil studi literatur diketahui faktor-faktor keunggulan pertambangan Sulawesi Tenggara dibanding provinsi lainnya, yang selanjutnya diformulasikan ke dalam sebuah tabel data, sehingga kekuatan dan kelemahan seluruh provinsi-provinsi yang dianalisis dapat diketahui.

Berdasarkan pernyataan Rohman (2015), setelah indikator-indikator SWOT diperoleh, langkah selanjutnya adalah menentukan bobot, bobot relatif, rating dan mengalikan bobot dengan rating, baik untuk kekuatan maupun kelemahan. Selanjutnya, ditentukan juga bobot, bobot relatif, rating dan mengalikan bobot dengan rating untuk peluang dan ancaman. Bobot ditentukan berdasarkan kondisi yang dimiliki Sulawesi Tenggara dengan skala 1 sampai 4 (1) tidak memengaruhi, 4 =sangat memengaruhi). Setelah diperoleh nilai bobot, selanjutnya dijumlahkan dan dihitung bobot relatif untuk masing-masing indikator dengan cara membagi masing-masing bobot dengan total bobot dari kekuatan dan kelemahan, peluang dan ancaman, sehingga hasil total nilai bobot relatif bila dijumlahkan menjadi 1,00 (100\%).

Setelah nilai bobot dan bobot relatif diperoleh, selanjutnya ditentukan rating (Tamara, 2016), yaitu kondisi yang memengaruhi Provinsi Sulawesi Tenggara. Pemberian nilai rating untuk variabel kekuatan dan peluang berkebalikan dengan variabel kelemahan dan ancaman.

Nilai rating untuk kekuatan dan peluang diberi nilai 1 sampai 4 . Nilai 1, kalau kondisi kinerjanya di bawah provinsi lainnya; nilai 2, kalau kondisi kinerjanya sama dengan provinsi lainnya; nilai 3 atau 4, kalau kondisi kinerjanya lebih baik dibanding provinsi lainnya. Semakin tinggi nilainya, artinya kinerja Sulawesi Tenggara semakin baik dibanding provinsi lainnya. Nilai rating kelemahan dan ancaman diberi nilai 1 sampai 
4. Nilai 1, kalau kondisi Sulawesi Tenggara semakin banyak kelemahannya dibanding provinsi lainnya; nilai 4, kalau kondisi Sulawesi Tenggara kelemahannya semakin menurun dibandingkan provinsi lainnya.

Setelah nilai bobot, bobot relatif dan rating diperoleh (Munawaroh and Suryana, 2013), lalu bobot dikalikan dengan rating. Langkah selanjutnya adalah menentukan komentar pada setiap variabel SWOT Dari hasil perhitungan nilai SWOT. Apabila total nilai untuk faktor internal/IFAS (Internal Factors Analysis Strategic) (kekuatan dan kelemahan) semakin mendekati 1, berarti semakin banyak kelemahan dibandingkan kekuatannya. Apabila nilainya mendekati 4, berarti semakin banyak kekuatan dibandingkan kelemahannya. Apabila total nilai faktor eksternal/EFAS (External Factors Analysis Strategic) (peluang dan ancaman) semakin mendekati 1, berarti semakin banyak ancaman dibandingkan peluangnya dan semakin mendekati 4 , berarti semakin banyak peluang dibandingkan ancamannya.

Metode perhitungan kondisi internal (IFAS) dan kondisi eksternal (EFAS) dapat dilihat pada Tabel 1. Menurut Rangkuti (2006), hasil perhitungan kemudian dimasukkan dalam
Internal External Matrix (analisis keterhubungan/ keterkaitan dalam matriks SWOT). Dari analisis keterhubungan ini dapat diketahui posisi Sulawesi Tenggara sebagai lokasi KEK pabrik pengolahan dan peleburan nikel, serta strategi yang tepat yang harus diambil oleh Sulawesi Tenggara, sehingga tujuan dijadikannya KEK dapat berhasil maksimal (Tabel 2).

\section{HASIL DAN PEMBAHASAN}

\section{Hasil}

\section{Kondisi Internal dan Eksternal Provinsi Sulawesi Tenggara}

Berdasarkan Pusat Sumber Daya Geologi (2016), Sulawesi Tenggara memiliki sumber daya nikel yang paling besar (1.616.868.929 ton) dibanding provinsi lainnya dari total sumber daya Indonesia sebesar 5.756.362.683 ton (Tabel 3). Provinsi lain yang memiliki sumber daya nikel antara lain, Maluku Utara (1.422.837.640 ton), Papua (1.291.866.483 ton), Sulawesi Tengah (691.373.716 ton), Sulawesi Selatan (563.281.051 ton) dan sebagian kecil di Papua Barat (114.301.887 ton) serta Kalimantan Timur (55.832.951 ton).

Tabel 1. Perhitungan IFAS dan EFAS

- IFAS (Internal Factors Analysis Strategic)

\begin{tabular}{|c|c|c|c|c|c|}
\hline Faktor-Faktor Strategi Internal & Bobot & $\begin{array}{l}\text { Bobot } \\
\text { Relatif }\end{array}$ & Rating & $\begin{array}{c}\text { Bobot } \mathrm{x} \\
\text { Rating }\end{array}$ & Komentar \\
\hline \multicolumn{6}{|l|}{ KEKUATAN (S) } \\
\hline \multicolumn{6}{|l|}{ Total Kekuatan } \\
\hline \multicolumn{6}{|l|}{ KELEMAHAN (W) } \\
\hline \multicolumn{6}{|l|}{ Total Kelemahan } \\
\hline \multicolumn{6}{|c|}{ Perhitungan EFAS (External Factors Analysis Strategic) } \\
\hline Faktor-Faktor strategi Eksternal & Bobot & $\begin{array}{l}\text { Bobot } \\
\text { Relatif } \\
\end{array}$ & Rating & $\begin{array}{l}\text { Bobot } \\
\text { Rating }\end{array}$ & Komentar \\
\hline 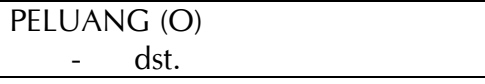 & & - & & & \\
\hline \multicolumn{6}{|l|}{ Total Peluang } \\
\hline \multicolumn{6}{|l|}{ ANCAMAN (T) } \\
\hline \multicolumn{6}{|l|}{ Total Ancaman } \\
\hline JUMLAH TOTAL O + T & & 1,0000 & & & \\
\hline
\end{tabular}


Tabel 2. Analisis keterkaitan dalam matriks SWOT (internal, external matrix)

\begin{tabular}{|c|c|c|}
\hline \multirow{2}{*}{$\begin{array}{c}\text { Faktor eksternal } \\
\text { (EFAS/external factors } \\
\text { analysis strategic) }\end{array}$} & \multicolumn{2}{|c|}{$\begin{array}{c}\text { Faktor internal } \\
\text { (IFAS/internal factors analysis strategic) }\end{array}$} \\
\hline & Strengths (S) & Weaknesses (W) \\
\hline Opportunities (O) & $\begin{array}{l}\text { Strategi SO (maxi-maxi) } \\
\text { Menciptakan strategi dengan } \\
\begin{array}{ll}\text { memanfaatkan kekuatan } \\
\text { mengambil peluang }(\mathrm{O}) .\end{array}\end{array}$ & $\begin{array}{l}\text { Strategi WO (mini-maxi) } \\
\text { Menciptakan strategi dengan } \\
\text { mengatasi kelemahan }(\mathrm{W}) \text { dengan } \\
\text { memanfaatkan peluang }(\mathrm{O}) \text {. }\end{array}$ \\
\hline Threats (T) & $\begin{array}{l}\text { Strategi ST (maxi-mini) } \\
\text { Menciptakan strategi dengan } \\
\begin{array}{ll}\text { memanfaatkan kekuatan } \\
\text { mengatasi ancaman }(\mathrm{T}) .\end{array}\end{array}$ & $\begin{array}{lr}\text { Strategi WT (mini-mini) } & \\
\text { Menciptakan strategi } & \text { dengan } \\
\text { mengatasi kelemahan } & \text { untuk } \\
\text { mengatasi ancaman }(\mathrm{T}) . & \end{array}$ \\
\hline
\end{tabular}

Sumber : Rangkuti (2006)

Tabel 3. Jumlah sumber daya nikel menurut provinsi (2016)

\begin{tabular}{llrr}
\hline No. & \multicolumn{1}{c}{ Provinsi } & $\begin{array}{c}\text { Sumber daya } \\
\text { (ton) }\end{array}$ & $\begin{array}{c}\text { Cadangan } \\
\text { (ton) }\end{array}$ \\
\hline $\mathbf{1}$ & Sulawesi Tenggara & $\mathbf{1 . 6 1 6 . 8 6 8 . 9 2 9}$ & $\mathbf{1 . 0 7 2 . 0 0 8 . 0 9 8}$ \\
2 & Maluku Utara & 1.422 .837 .640 & 1.221 .166 .233 \\
3 & Papua & 1.291 .866 .483 & --- \\
4 & Sulawesi Tengah & 691.373 .716 & 561.648 .081 \\
5 & Sulawesi Selatan & 563.281 .051 & 342.536 .526 \\
6 & Papua Barat & 114.301 .887 & -- \\
7 & Kalimantan Timur & 55.832 .915 & -- \\
\hline
\end{tabular}

Sumber : Pusat Sumber Daya Geologi (2016)

Keberadaan sumber daya nikel di wilayah Sulawesi Tenggara paling besar dibanding provinsi lainnya, namun belum memberikan manfaat yang signifikan bagi perekonomian wilayah tersebut. Hal ini disebabkan masih kurangnya kegiatan eksplorasi yang dilakukan, sehingga sumber daya tersebut belum bisa menjadi cadangan yang siap tambang. Di samping itu, nikel yang sudah diproduksi diekspor dalam bentuk mentah (Haryadi, 2017). Berdasarkan data dari Direktorat Jenderal Mineral dan Batubara (2017), sumber daya nikel yang besar ini direncanakan dapat mendukung rencana pembangunan 20 pabrik pengolahan dan pemurnian nikel di provinsi ini hingga lebih dari 25 tahun, dengan tingkat kebutuhan rata-rata bahan baku untuk seluruh pabrik pengolahan dan pemurnian nikel sebesar 12.494.722 ton setiap tahunnya.

Menurut Gunawan and Maryoni (2017), sumber daya yang besar di Sulawesi Tenggara harus dimanfaatkan secara optimal dan dapat menjadi kekuatan bagi wilayah untuk mengembangkan ekonomi yang riil, juga sebagai daya dukung bagi keberlangsungan pemasokan bahan baku bagi pabrik pengolahan dan pemurnian nikel di wilayah tersebut.

Dari sisi perekonomian, menurut Badan Pusat Statistik (2017), Produk Domestik Regional Bruto (PDRB) Provinsi Sulawesi Tenggara pada tahun 2016 menempati posisi kelima dari tujuh provinsi yang dianalisis dengan nilai Rp. 77,739 triliun. PDRB ini menggambarkan tingkat kemampuan suatu provinsi untuk menciptakan nilai tambah pada tahun tertentu. Provinsi yang memiliki nilai PDRB tertinggi pada tahun 2016 adalah Kalimantan Timur (Rp. 438,977 triliun), selanjutnya Sulawesi Selatan (Rp. 269,338 triliun), Papua (Rp. 142,467 triliun), Sulawesi Tengah (Rp. 91,070 triliun), sedangkan Provinsi yang PDRB-nya di bawah Sulawesi Tenggara adalah Papua Barat (Rp. 54,711 triliun) dan Maluku Utara (Rp. 21,560 triliun), Tabel 4. 
Tabel 4. Produk Domestik Regional Bruto (PDRB) atas dasar harga konstan tahun 2010 menurut provinsi (miliar rupiah, 2014-2016)

\begin{tabular}{|c|c|c|c|c|}
\hline No. & Provinsi & 2014 & 2015 & 2016 \\
\hline 1 & Kalimantan Timur & $446.029,00$ & $440.647,70$ & $438.977,00$ \\
\hline 2 & Sulawesi Selatan & $233.988,10$ & $250.758,30$ & $269.338,50$ \\
\hline 3 & Papua & $121.391,20$ & $130.459,90$ & $142.467,40$ \\
\hline 4 & Sulawesi Tengah & $71.677,50$ & $82.803,20$ & $91.070,60$ \\
\hline 5 & Sulawesi Tenggara & $68.291,80$ & $72.991,3$ & $77.739,50$ \\
\hline 6 & Papua Barat & $50.259,90$ & $52.346,50$ & $54.711,30$ \\
\hline 7 & Maluku Utara & $19.208,80$ & $20.381,00$ & $21.560,30$ \\
\hline
\end{tabular}

Sumber : Badan Pusat Statistik (2017)

Menurut Sihaloho dan Muna (2010), jumlah penduduk yang besar dan sebagian besar merupakan jumlah angkatan yang bekerja dengan maksud memperoleh atau membantu memperoleh pendapatan atau keuntungan, merupakan dua faktor utama untuk mendukung keberadaan pembangunan KEK pabrik pengolahan dan pemurnian nikel di Sulawesi Tenggara. Menurut data Badan Pusat Statistik (2017), Sulawesi Tenggara berada di peringkat ketiga dengan persentase angkatan kerja sebesar $(49,14 \%)$. Provinsi yang persentase angkatan kerjanya lebih tinggi dari Sulawesi Tenggara adalah Papua $(53,69 \%)$ dan Sulawesi Tengah $(51,66 \%)$, sedangkan yang lebih rendah adalah Papua Barat $(49,11 \%)$, Kalimantan Timur $(49,06 \%)$, Sulawesi Selatan $(45,09 \%)$ dan Maluku Utara $(44,23 \%)$. Besarnya jumlah penduduk usia produktif atau jumlah angkatan kerja secara signifikan ikut mendorong naiknya pendapatan per kapita provinsi bersangkutan (Tabel 5).

Pendukung lainnya dalam pembentukan KEK adalah sektor konstruksi (Sekretariat Dewan Nasional Kawasan Ekonomi Khusus, 2013). Jenis pekerjaan yang termasuk dalam kegiatan sektor konstruksi terdiri dari konstruksi bangunan gedung (seluruh gedung-gedung industri dan gedung tempat tinggal), konstruksi bangunan sipil (seluruh infrastruktur, jalan, jembatan, landasan kereta api, pelabuhan, dermaga, konstruksi telekomunakasi dan lain-lain) dan konstruksi bangunan khusus (fondasi dan pilar, pembuatan/pengeboran sumur air tanah, pemasangan perancah (steiger), pemasangan atap/bangunan konstruksi/dan kerangka baja, pengerukan dan konstruksi lainnya. Berdasarkan data Badan Pusat Statistik (2017), pada tahun 2016, jumlah perusahaan konstruksi di Sulawesi Tenggara sebanyak 3.480 buah menempati posisi ketiga dibanding Sulawesi Selatan sebanyak 7.366 buah dan Kalimantan Timur sebanyak 5.224 buah. Provinsi lainnya yang berada di bawah Sulawesi Tenggara, antara lain Papua 3.050 buah, Sulawesi Tengah 2.864 buah, Maluku Utara 2.081 buah dan Papua Barat sebanyak 1.382 buah (Tabel 6).

Dari dukungan ketersediaan energi listrik (Tabel 7), Sulawesi Tenggara memiliki kapasitas terpasang (pembangkit listrik yang dioperasikan) sebesar 127,47 MW, jumlah tenaga listrik yang dibangkitkan 846,29 watt per jam dan listrik yang didistribusikan (listrik yang terjual) sebesar 703,59 MW dan menempati posisi kelima dari provinsi lainnya. Provinsi yang memiliki ketersediaan energi yang lebih besar dari Sulawesi Tenggara adalah Sulawesi Selatan dengan kapasitas terpasang (1.232,35 MW), Kalimantan Timur (1.053,03 MW), Sulawesi Tengah $(421,12 \mathrm{MW})$, Papua $(271,14 \mathrm{MW})$; sedangkan provinsi lainnya yang berada di bawah Sulawesi Tenggara, yaitu Papua Barat $(112,76 \mathrm{MW})$ dan Maluku Utara (73,81 MW).

Dalam masalah sosial dan keamanan sangat diperlukan untuk mendukung keberadaan KEK pabrik pengolahan nikel, karena perusahaan dapat tertarik membangun pabrik pengolahan, apabila situasi kondusif dan mendukung, sehingga dapat memberikan keuntungan finansial bagi perusahaan (Destaningtyas, 2010). Pada tahun 2016 (Badan Pusat Statistik, 2017), kondisi keamanan sosial atau jumlah tindak pidana di Sulawesi Tenggara menempati kondisi keamanan kelima dengan jumlah tindak pidana sebanyak (3.756 kejadian). Provinsi yang paling banyak terjadinya tindak pidana atau tingkat kemanan sosialnya buruk adalah Sulawesi Selatan (15.071 kejadian), Sulawesi Tengah (9.602 kejadian), Kalimantan Timur 
(8.896 kejadian), Papua (8.103 kejadian); sedangkan provinsi yang tingkat kemanannya sangat baik dan kondusif adalah Maluku Utara
(1.095 kejadian) dan Papua Barat (3.123 kejadian), seperti terlihat pada Tabel 8.

Tabel 5. Jumlah penduduk dan jumlah angkatan kerja menurut provinsi (2016)

\begin{tabular}{llrrr}
\hline No. & \multicolumn{1}{c}{ Provinsi } & $\begin{array}{c}\text { Jumlah } \\
\text { penduduk }\end{array}$ & $\begin{array}{c}\text { Jumlah } \\
\text { angkatan kerja }\end{array}$ & $\begin{array}{c}\text { Persentase } \\
\text { angkatan kerja }\end{array}$ \\
\hline 1 & Papua & 3.207 .400 & 1.722 .162 & $53,69 \%$ \\
2 & Sulawesi Tengah & 2.921 .700 & 1.509 .505 & $51,66 \%$ \\
$\mathbf{3}$ & Sulawesi Tenggara & $\mathbf{2 . 5 5 1 . 0 0 0}$ & $\mathbf{1 . 2 5 3 . 6 2 4}$ & $\mathbf{4 9 , 1 4 \%}$ \\
4 & Papua Barat & 893.400 & 438.817 & $49,11 \%$ \\
5 & Kalimantan Timur & 3.501 .200 & 1.717 .892 & $49,06 \%$ \\
6 & Sulawesi Selatan & 8.606 .400 & 3.881 .003 & $45,09 \%$ \\
7 & Maluku Utara & 1.185 .900 & 524.526 & $44,23 \%$ \\
\hline
\end{tabular}

Sumber : Badan Pusat Statistik (2017)

Tabel 6. Jumlah perusahaan konstruksi menurut provinsi $(2015,2016)$

\begin{tabular}{llrr}
\hline No. & \multicolumn{1}{c}{ Provinsi } & $\begin{array}{c}2015 \\
\text { (perusahaan) }\end{array}$ & $\begin{array}{c}2016 \\
\text { (perusahaan) }\end{array}$ \\
\hline 1 & Sulawesi Selatan & 7.311 & 7.366 \\
2 & Kalimantan Timur & 5.119 & 5.224 \\
$\mathbf{3}$ & Sulawesi Tenggara & $\mathbf{2 . 6 7 8}$ & $\mathbf{3 . 4 8 0}$ \\
4 & Papua & 3.047 & 3.050 \\
5 & Sulawesi Tengah & 2.800 & 2.864 \\
6 & Maluku Utara & 1.874 & 2.081 \\
7 & Papua Barat & 1.389 & 1.382 \\
\hline
\end{tabular}

Sumber : Badan Pusat Statistik (2017)

Tabel 7. Ketersediaan energi listrik menurut provinsi (2016)

\begin{tabular}{llrrr}
\hline No. & \multicolumn{1}{c}{ Provinsi } & $\begin{array}{c}\text { Kapasitas terpasang } \\
(\mathrm{MW})\end{array}$ & $\begin{array}{c}\text { Tenaga listrik yang } \\
\text { dibangkitkan }\end{array}$ & $\begin{array}{c}\text { Listrik yang } \\
\text { didistribusikan }\end{array}$ \\
\hline 1 & Sulawesi Selatan & $1.232,35$ & $5.978,87$ & $4.479,46$ \\
2 & Kalimantan Timur & $1.053,03$ & $2.450,57$ & $3.007,30$ \\
3 & Sulawesi Tengah & 421,12 & $1.580,22$ & 948,78 \\
4 & Papua & 271,14 & 917,48 & $\mathbf{7 6 3 , 3 2}$ \\
$\mathbf{5}$ & Sulawesi Tenggara & $\mathbf{1 2 7 , 4 7}$ & $\mathbf{8 4 6 , 2 9}$ & $\mathbf{7 0 3 , 5 9}$ \\
6 & Papua Barat & 112,76 & 447,95 & 455,58 \\
7 & Maluku Utara & 73,81 & 170,35 & 329,44 \\
\hline
\end{tabular}

Sumber : Badan Pusat Statistik (2017)

Tabel 8. Kondisi keamanan sosial (jumlah tindak pidana informasi Kepolisian Daerah) menurut provinsi (2014-2016)

\begin{tabular}{llrrr}
\hline No. & \multicolumn{1}{c}{ Provinsi } & 2014 & 2015 & \multicolumn{2}{c}{2016} \\
\hline 1 & Sulawesi Selatan & 14.925 & 16.088 & 15.071 \\
2 & Sulawesi Tengah & 7.804 & 8.988 & 9.602 \\
3 & Kalimantan Timur & 9.095 & 8.764 & 8.896 \\
4 & Papua & 8.870 & 7.194 & 8.103 \\
$\mathbf{5}$ & Sulawesi Tenggara & $\mathbf{5 . 2 8 4}$ & $\mathbf{3 . 6 5 5}$ & $\mathbf{3 . 7 5 6}$ \\
6 & Papua Barat & 1.328 & 1.356 & 3.123 \\
7 & Maluku Utara & 1.124 & 814 & 1.095 \\
\hline
\end{tabular}

Sumber : Badan Pusat Statistik (2017) 


\section{Pengembangan Kawasan Ekonomi Khusus}

Dalam Pasal 31, UU 25/2007 tentang Penanaman Modal menyebutkan adanya pengaturan KEK sebagai bagian dari kegiatan penanaman modal di Indonesia. Menurut Setyawan (2010), KEK dibentuk untuk menyelenggarakan fungsi perekonomian dan memperoleh fasilitas tertentu yang ditujukan untuk melipatgandakan pertumbuhan ekonomi nasional, serta memberikan dampak yang besar pada peningkatan lapangan kerja dalam negeri. Menurut Pramoda dan Apriliani (2016), pengertian KEK adalah kawasan tempat pemusatan kegiatan industri yang dilengkapi dengan sarana dan prasarana penunjang yang dikembangkan dan dikelola oleh perusahaan kawasan industri yang telah memiliki izin usaha kawasan industri. Sedangkan menurut Purba (2006), KEK adalah kawasan yang ditetapkan untuk menyelenggarakan fungsi perekonomian dan memperoleh fasilitas tertentu, yang memiliki keunggulan geoekonomi dan geostrategi dan berfungsi untuk menampung kegiatan industri, ekspor, impor, dan kegiatan ekonomi lain yang memiliki nilai ekonomi tinggi dan daya saing internasional.

Menurut UU 39/2009 Pasal 4, KEK harus memenuhi kriteria: sesuai dengan Rencana Tata Ruang Wilayah dan tidak berpotensi mengganggu kawasan lindung; pemerintah provinsi/kabupaten/kota yang bersangkutan (para pemangku kepentingan) mendukung KEK (melalui kelembagaan/insentif/ kemudahan birokrasi/menyediakan infrastruktur); terletak pada posisi yang dekat dengan jalur perdagangan internasional atau dekat dengan jalur pelayaran internasional; terletak pada wilayah potensi sumber daya unggulan; dan mempunyai batas yang jelas. Jika melihat UU 39/2009 Pasal 4, maka Sulawesi Tenggara memenuhi syarat sebagai pemilik sumber daya unggulan nikel untuk membangun KEK pabrik pengolahan dan pemurnian nikel. Menurut Suhandi, Susanto dan Hutamadi (2011), potensi bahan galian nikel di Kabupaten Konawe, Provinsi Sulawesi Tenggara saat ini mulai banyak diusahakan oleh perusahaanperusahaan tambang, dengan beroperasinya sejumlah tambang di berbagai wilayah kecamatan, seperti di Kecamatan Puriala dan Pondidaha.
Pada dasarnya, KEK dibentuk untuk: membuat lingkungan kondusif bagi akitivitas investasi, ekspor, dan perdagangan; meningkatkan daya saing produk dan daya saing wilayah (Rahayu dan Retnani, 2016). Selain itu, KEK juga berperan sebagai katalis reformasi ekonomi; mendorong pertumbuhan ekonomi dan industri daerah; peningkatan lapangan pekerjaan, penurunan tingkat kemiskinan dan peningkatan kesejahteraan masyarakat regional; pemerataan ekonomi, terutama dari sudut pandang pendapatan (mengurangi kesenjangan ekonomi) (Sumiati, 2015). Menurut Sudirman (2011), KEK dibentuk untuk mempercepat pembangunan; mengendalikan tata ruang wilayah; memberikan kepastian lokasi dalam perencanaan dan pembangunan infrastruktur yang terkoordinasi antarsektor terkait; meningkatkan efisiensi sistem logistik dan sebagai pergerakan utama pusat-pusat pertumbuhan ekonomi baru.

Dari seluruh kondisi internal dan eksternal yang dimiliki Sulawesi Tenggara, selanjutnya dilakukan analisis SWOT. Dari hasil analisis internal, dapat dijelaskan sebagai berikut :

a. Berdasarkan perhitungan pada Tabel 10 IFAS, dapat dilihat bahwa kekuatankekuatan yang dimiliki sektor pertambangan nikel Sulawesi Tenggara cukup besar, di antaranya adalah sumber daya mineral nikel yang besar (nilai bobot 0,59), Sumber Daya Manusia yang besar (nilai bobot 0,33 ), iklim investasi yang baik $(0,14)$ dan pengelolaan kemampuan lingkungan yang baik dibanding Sulawesi Tengah, Sulawesi Selatan, Maluku Utara, Papua, dan Papua Barat $(0,22)$.

b. Dari Tabel 10 tersebut juga terlihat adanya kelemahan-kelemahan berupa infrastruktur yang tidak memadai (nilai sekor 0,33), rendahnya penerapan sanksi terhadap perusahaan yang wanprestasi (nilai skor $0,15)$ serta lemahnya birokrasi perizinan dengan banyaknya punggutan liar serta masalah perizinan yang berbelit-belit (nilai skor 0,15$)$.

c. Kebijakan hilirisasi atau peningkatan nilai tambah sulit untuk diterapkan dan terus mendapat penentangan dari para pengusaha tambang. Oleh karena itu, sektor pertambangan nikel harus memanfaatkan kekuatan dan peluang yang dimiliki untuk menjadikan tantangan menjadi peluang dan mengatasi 
kelemahan-kelemahan yang ada, sehingga dapat tercipta sektor pertambangan nikel yang mampu menghasilkan produk hasil tambang olahan yang sesuai dengan spesifikasi yang diinginkan oleh industri penggunanya, baik di dalam negeri maupun di pasar ekspor.

Setelah melakukan perhitungan internal, selanjutnya dilakukan perhitungan analisis eksternal, yang hasilnya dapat dilhat pada Tabel 11.

a. Dari perhitungan Tabel 11 EFAS dapat dilihat nilai faktor pembobotan untuk peluang yang paling tinggi adalah jumlah penduduk Indonesia yang besar yang menjadi peluang pasar yang besar di dalam negeri maupun pasar ekspor dengan skor pembobotan sebesar 0,46 serta pertumbuhan ekonomi Indonesia yang stabil dengan skor 0,35.

b. Kalau kondisi SDM tidak ditingkatkan menjadi unggul dan tidak ada modernisasi teknologi serta peningkatan investasi, maka hal ini menjadi ancaman bagi sektor pertambangan mineral nikel di Sulawesi Tenggara, karena adanya tingkat persaingan yang tinggi dari negara-negara penghasil olahan nikel lainnya dengan bobot skor sebesar 0,46, serta kekurangan bahan baku untuk produksi yang besar, yang membutuhkan bahan baku nikel yang besar dengan harga tinggi, dan kondisi ini memiliki tingkat skor sebesar 0,34 .

Dari hasil analisis faktor internal dan eksternal, selanjutnya dilakukan analisis keterkaitan kondisi internal (IFAS) dan kondisi eksternal (EFAS) yang dapat lihat pada Tabel 9. Matriks keterkaitan analisis IFAS dan EFAS adalah:

a. Dari analisis keterkaitan dalam matriks SWOT di atas dihasilkan 4 strategi, yakni strategi SO (Maxi-Maxi), Strategi ST (MaxiMini), Strategi WO (Mini-Maxi) dan strategi WT (Mini-Mini) sebagaimana diuraikan dalam Tabel 12.

b. Dari perhitungan di atas bisa dikatakan bahwa sektor pertambangan nikel di Sulawesi Tenggara memiliki kekuatan yang cukup baik, berdasarkan perhitungan IFAS, mempunyai kekuatan dengan poin 1,63.

c. Kelemahan sektor pertambangan nikel di Sulawesi Tenggara dengan poin 1,00. Angka ini cukup besar untuk kategori kelemahan. Selisih kekuatan dan kelemahan ini cukup besar, dengan skor 0,63 . Hal ini dapat dijadikan acuan bagi sektor pertambangan nikel di Sulawesi Tenggara dalam menetapkan kebijakankebijakan baru yang lebih kreatif dan inovatif, sehingga kekuatan yang dimiliki dapat dimanfaatkan dengan baik dan kelemahan yang dimiliki dapat diminimalisasi.

d. Berdasarkan perhitungan EFAS, peluang mempunyai poin 1,27. Angka ini cukup besar walaupun masih jauh dari angka tertinggi yang mampu dimiliki sektor ini, yaitu 4. Hal ini menunjukkan bahwa untuk memajukan sektor ini, masih perlu untuk mencari peluang-peluang lain.

e. Ancaman sektor pertambangan mineral nikel di Sulawesi Tenggara dengan skor 1,19 poin, merupakan angka yang cukup besar. Selisih antara peluang dan ancaman adalah 0,08. Berdasarkan perhitungan ini, ada banyak hal yang masih harus diupayakan sektor ini agar dapat mengatasi ancaman yang ada.

f. Hasil analisis SWOT menunjukkan bahwa keadaan sektor pertambangan nikel di Sulawesi Tenggara masih terdapat beberapa hal yang harus diperbaiki untuk membangun KEK pabrik pengolahan dan peleburan nikel.

Tabel 9. Hasil Perhitungan keterkaitan IFAS dan EFAS

\begin{tabular}{cccc}
\hline IFAS & 2,63 & EFAS & 2,46 \\
Total Skor Kekuatan (S) & 1,63 & Total Skor peluang (O) & 1,27 \\
Total Skor Kelemahan (W) & 1,00 & Total Skor Ancaman (T) & 1,19 \\
S - W & 0,63 & O - T & 0,08 \\
\hline
\end{tabular}




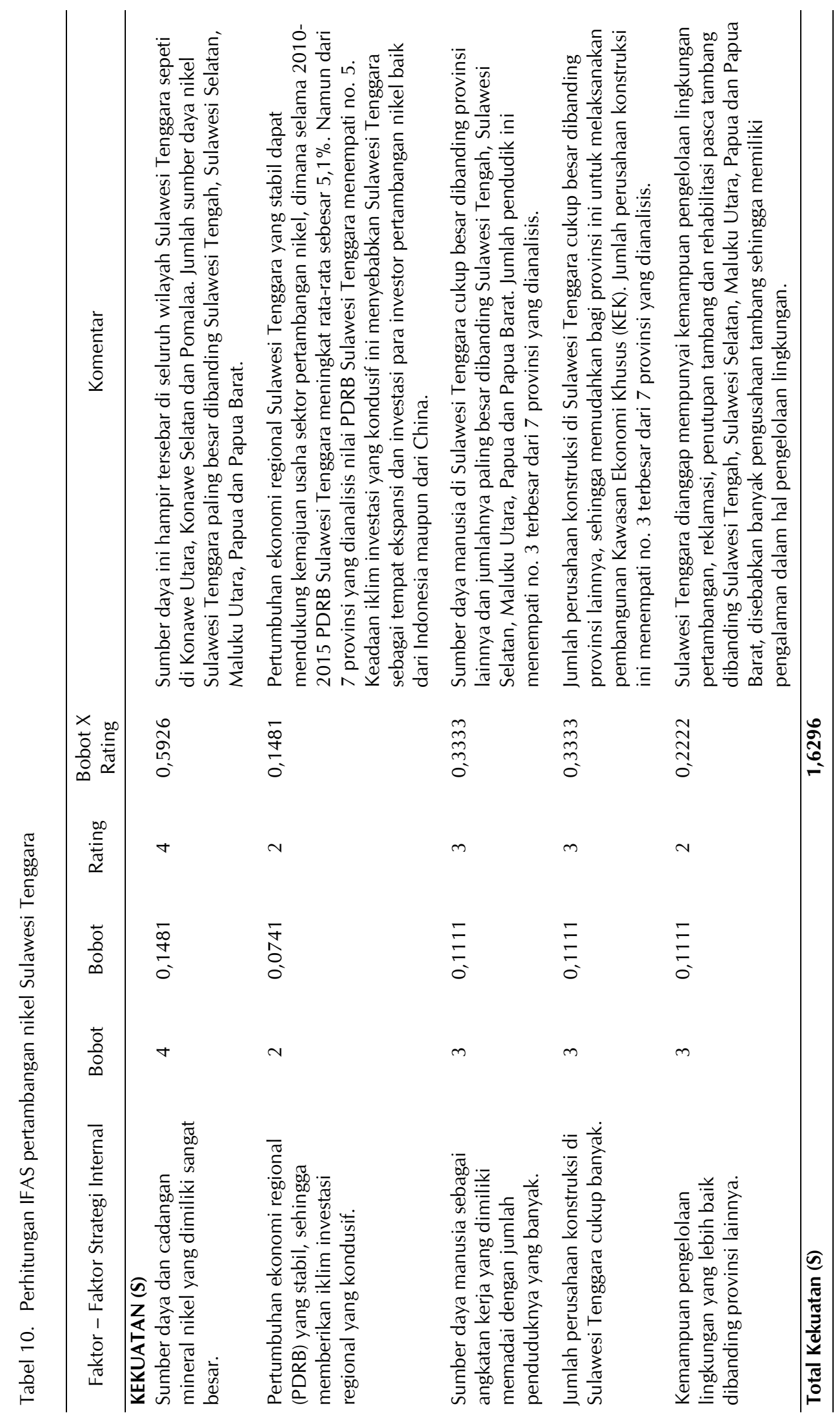









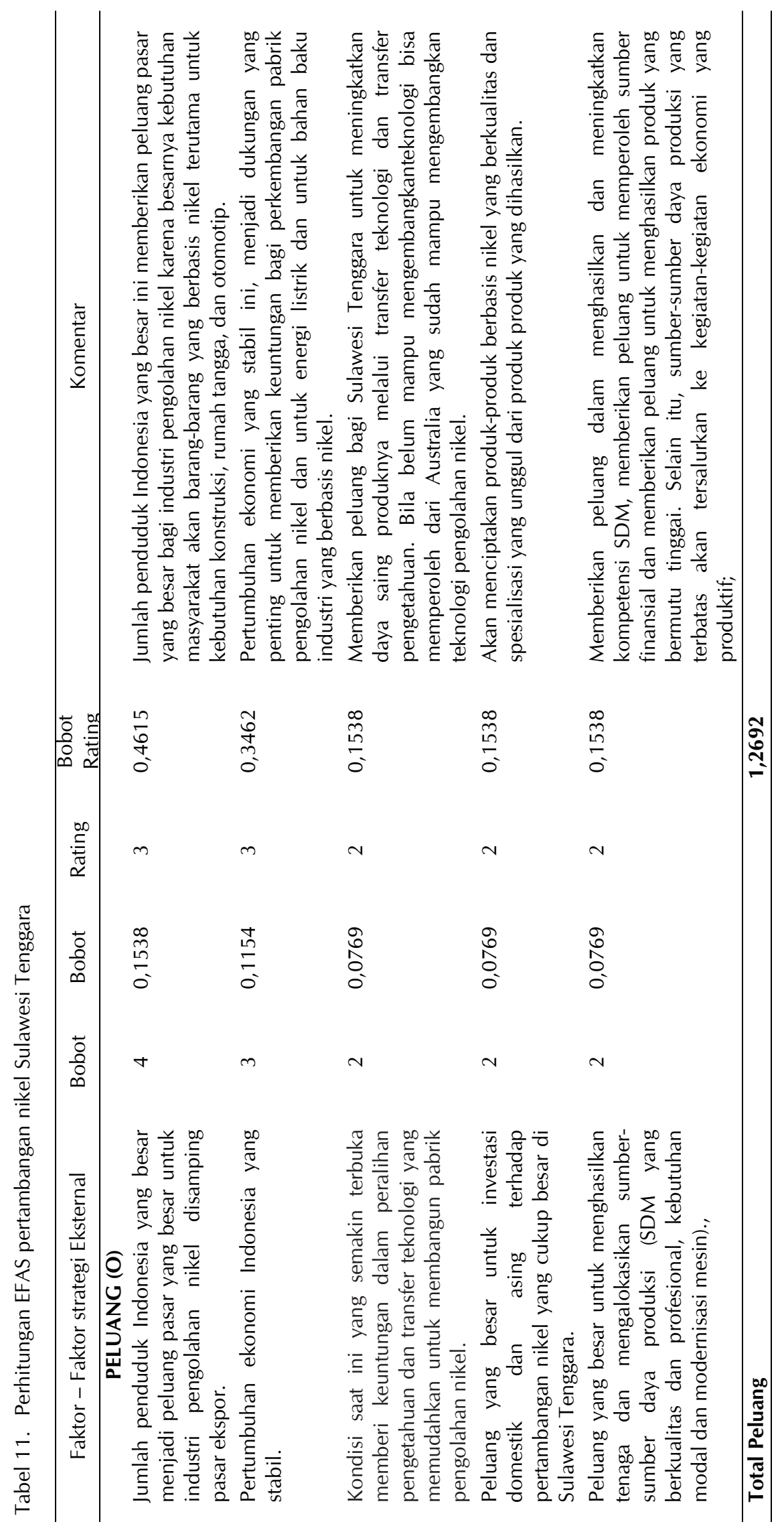




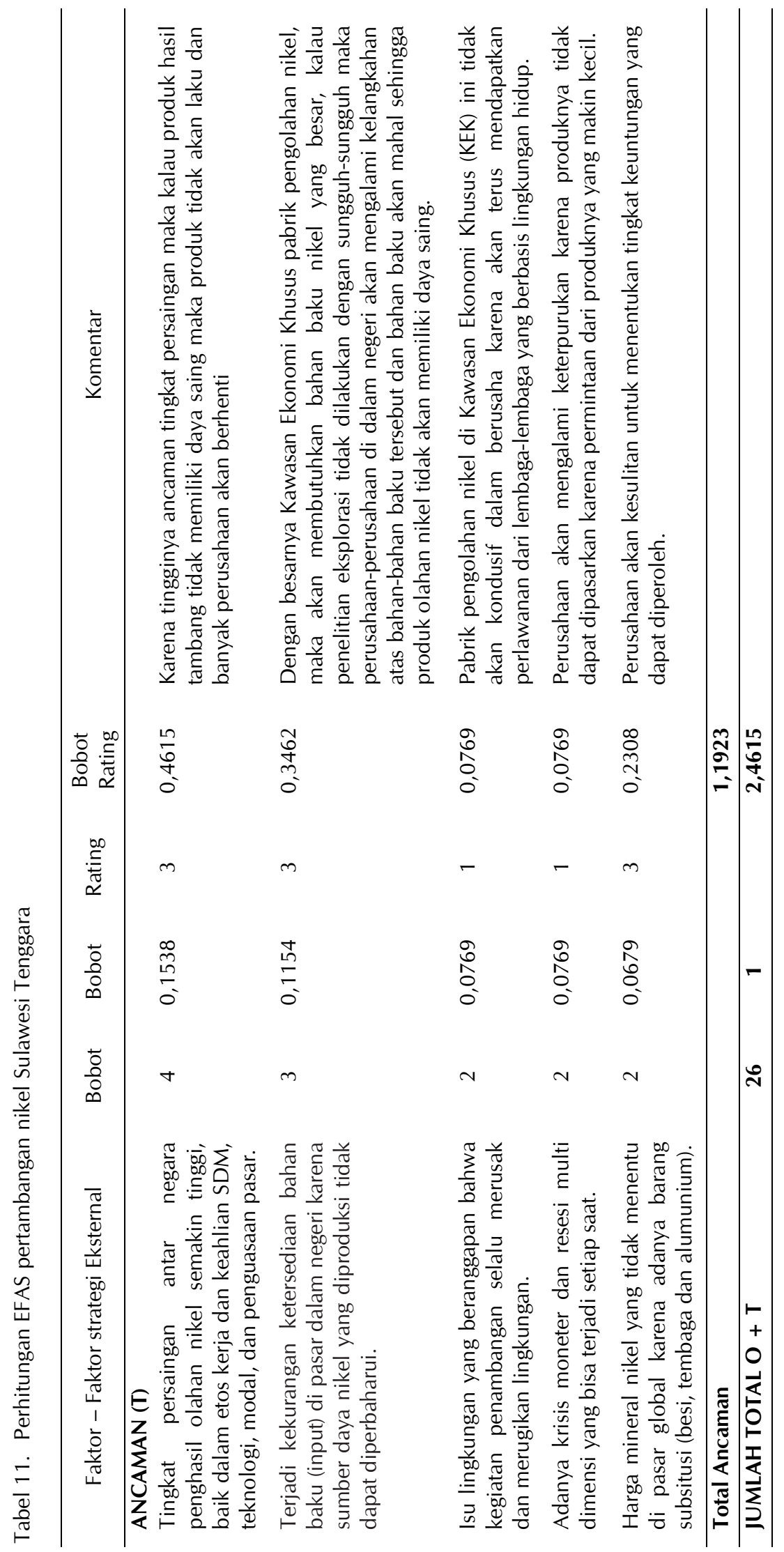




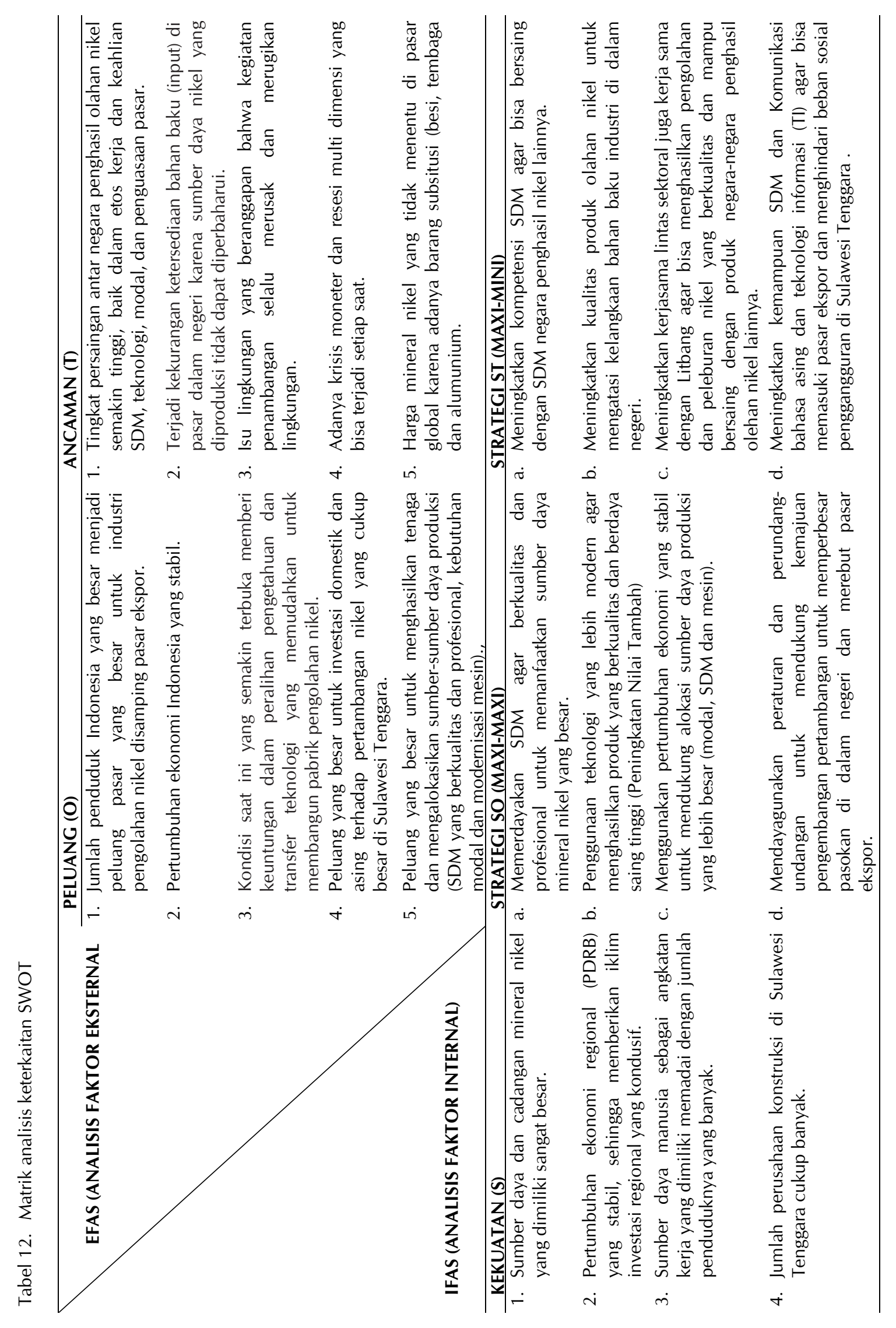




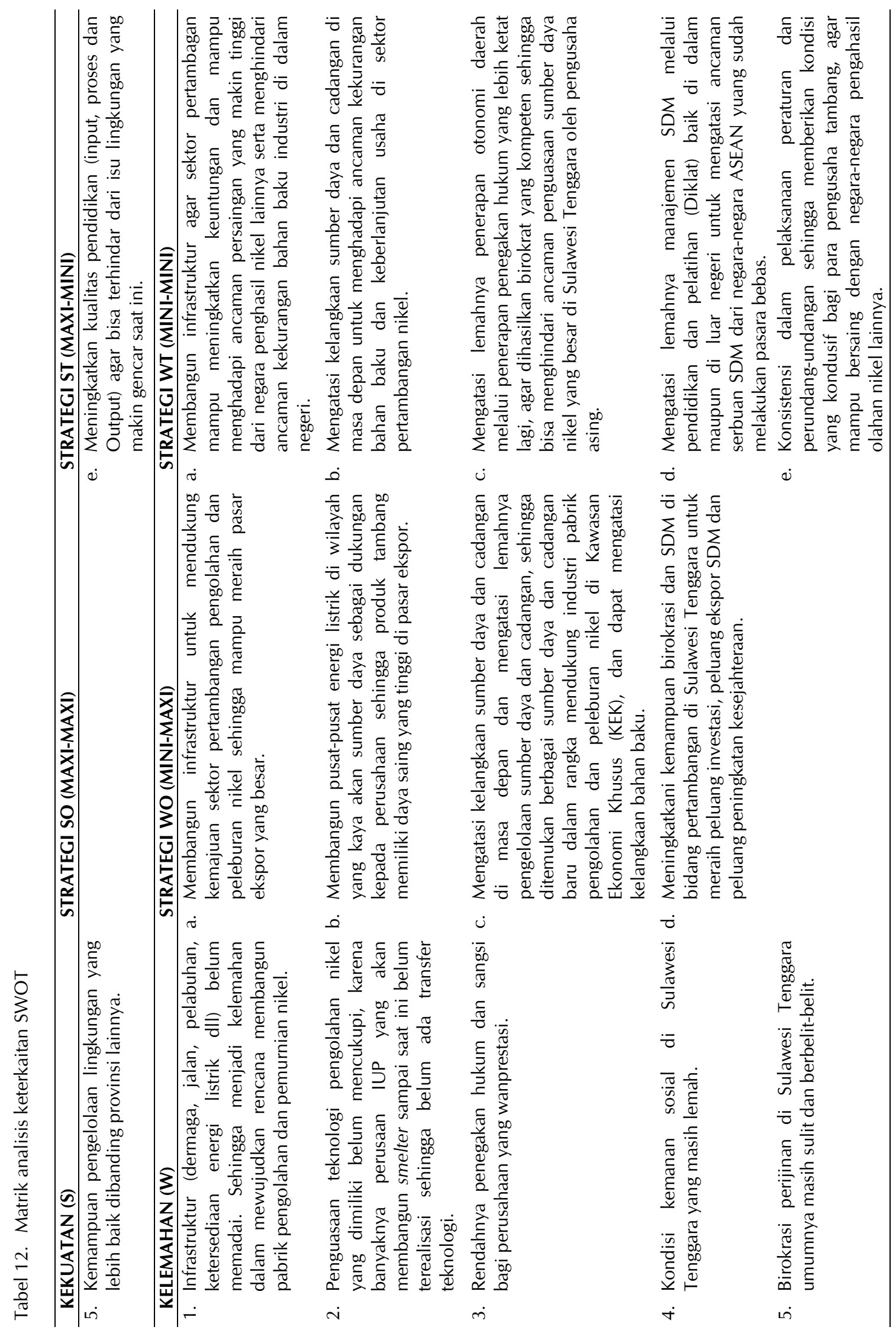




\section{PEMBAHASAN}

Berdasarkan data Pusat Sumber Daya Geologi (2016), Indonesia memiliki sumber daya bijih nikel yang besar dengan jumlah 5.756.362.683 ton, yang tersebar di Sulawesi Tenggara (1.616.868.929 ton), Maluku Utara (1.422.837.640 ton), Papua (1.291.866.483 ton), Sulawesi Tengah (691.373.716), Sulawesi Selatan (563.281.051) dan sebagian kecil di Papua Barat (114.301.887) serta Kalimantan Timur (55.832.951 ton). Sumber daya ini belum memberikan manfaat ekonomi yang signifikan, karena sebagian besar diekspor dalam bentuk mentah, harganya murah dan nilai perolehan ekonominya rendah, sehingga Indonesia kehilangan nilai tambah yang tinggi. Sesuai amanat UU 4/2009, para pengusaha pemegang IUP dan IUPK nikel wajib membangun pabrik pengolahan dan pemurnian bijih nikel di dalam negeri. Oleh karena itu, pemerintah wajib menyediakan lokasi khusus atau KEK untuk pabrik pengolahan dan pemurnian bijih nikel. Pemerintah merencanakan pembangun KEK pabrik pengolahan dan pemurnian nikel yang terintegrasi di Sulawesi Tenggara.

Dari hasil analisis, Sulawesi Tenggara sangat tepat dijadikan KEK pabrik pengolahan dan pemurnian nikel, karena memiliki pasokan bahan baku hingga lebih dari 25 tahun. Agar KEK ini berjalan sukses, maka harus didukung dengan perbaikan infrastruktur, dukungan energi, peningkatan keahlian SDM, dan penguasaan teknologi serta penggunaan peralatan yang modern, kemampuan inovasi dan dukungan finansial serta regulasi dari pemerintah (Badan Perencanaan Nasional, 2016). Terbentuknya KEK yang terintegrasi di Sulawesi Tenggara akan memberikan efek pengganda yang positif, antara lain:

a. Membangun daya saing Sulawesi Tenggara dengan memanfaatkan potensi sumber daya nikel yang besar yang dimilikinya melalui proses pengolahan dan pemurnian, sehingga memiliki nilai ekonomi dan nilai guna yang tinggi (Permana, 2010).

b. Memberikan dampak efek pengganda yang positif terhadap perokonomian dan sosial baik bagi daerah operasional tambang, maupun daerah nonoperasional dalam satu wilayah provinsi, dan dampak positif secara nasional (Haryadi, 2016). c. Meningkatkan kesejahteraan regional dan nasional, karena menjadi kawasan pusat industri pertambangan nasional, mengingat wilayah ini memiliki berbagai sumber daya mineral dan energi yang cukup beragam dan memiliki nilai ekonomi yang cukup tinggi (Wahyuni dan Wahyuningsih, 2016).

d. Akan menjadi kekuatan bagi Sulawesi Tenggara untuk mengembangkan ekonomi yang riil, juga sebagai daya dukung bagi keberlangsungan pemasokan bahan baku bagi pabrik pengolahan dan pemurnian nikel di wilayah tersebut (Gunawan dan Maryoni, 2017).

e. Mempercepat pembangunan dan mengurangi kesenjangan ekonomi dalam masyarakat melalui peningkatan kesempatan kerja dengan upah yang tinggi (Sihaloho dan Muna, 2010).

f. Membuat lingkungan kondusif bagi aktivitas investasi, ekspor, dan perdagangan produk pengolahan dan peleburan nikel, mengendalikan tata ruang, meningkatkan upaya industri yang berwawasan lingkungan, mempercepat pertumbuhan industri di daerah dan pembangunan infrastruktur yang terkoordinasi antarsektor terkait (Sekretariat Dewan Nasional Kawasan Ekonomi Khusus, 2013).

\section{KESIMPULAN DAN SARAN}

\section{Kesimpulan}

Dibanding provinsi lain, Sulawesi Tenggara memiliki sumber daya nikel paling besar, sehingga memiliki keunggulan yang bisa menjadikan provinsi tersebut menguasai pasar dan memiliki daya saing tinggi untuk dijadikan KEK pabrik pengolahan dan peleburan nikel dibanding provinsi lainnya (Sulawesi Tengah, Sulawesi Selatan, Maluku Utara, Papua, Papua Barat dan Kalimantan Timur). Penempatan KEK di Sulawesi Tenggara juga sudah sesuai dengan kriteria yang disyaratkan oleh UU 39/2009, Pasal 4, yakni KEK harus terletak pada wilayah yang memiliki potensi sumber daya unggulan. Selain itu, pembentukan KEK di Sulawesi Tenggara, sesuai dengan penelitian dari Syahza and Suarman (2013), sebagai salah satu strategi untuk mengembangkan perekonomian provinsi tersebut yang memiliki sumber daya bahan baku nikel yang besar dalam upaya percepatan pembangunan ekonominya. 


\section{Saran}

Dari hasil analisis SWOT, disarankan untuk melaksanakan :

a. Strategi SO, yaitu mendayagunakan SDM yang berkualitas dan profesional serta penggunaan teknologi yang modern untuk memanfaatkan sumber daya dan cadangan nikel yang dimilikinya.

b. Strategi ST, yaitu mendayagunakan SDM yang berkualitas dan profesional serta penggunaan teknologi yang modern untuk meningkatkan sumber dayanya dalam menghadapi ancaman kekurangan input bahan baku akibat provinsi lainnya tidak mau memasoknya.

c. Strategi WO, dengan memperbaiki segala kelemahan, antara lain memperbaiki infrastruktur, mengatasi kekurangan energi untuk menghasilkan produk yang bernilai tinggi dalam rangka meraih peluang pasar ekspor yang besar dan untuk memasok bahan baku industri dalam negeri.

d. Strategi WT, yaitu mempercepat pembangunan infrastruktur, pembangunan energi untuk menghasilkan produk yang bermutu tinggi untuk menghadapi ancaman persaingan di pasar ekspor dan untuk menghadapi ancaman kekurangan bahan baku.

e. Hasil analisis ini dapat dijadikan masukan rumusan kebijakan bagi pemerintah dalam upaya menentukan KEK pabrik pengolahan dan pemurnian nikel di Sulawesi Tenggara.

\section{UCAPAN TERIMA KASIH}

Penulis mengucapkan terima kasih kepada seluruh jajaran Dinas Pertambangan dan Energi Provinsi Sulawesi Tenggara, Maluku Utara, Papua dan beberapa perusahaan tambang di Sulawesi Tenggara, atas bantuan data dan informasi yang telah diberikan, sehingga penulis dapat menyelesaikan karya tulis ilmiah ini.

\section{DAFTAR PUSTAKA}

Amalia, A. (2016) "Perencanaan strategis pemasaran dengan pendekatan bauran pemasaran dan SWOT pada perusahaan POPSY TUBBY," Jurnal Performa, 1(3), pp. 297-306. Available at: https://journal.uc.ac.id/index.php/performa/arti cle/view/172.

Arminsyurita (2014) "Analisis strategi pemasaran jamur rimba Jaya Mushroom," Transparansi, 6(2), pp. 156-168. Available at: http://ojs.stiami.ac.id/index.php/transparansi/a rticle/view/39.

Badan Perencanaan Nasional (2016) "Prioritas nasional percepatan pertumbuhan kawasan ekonomi khusus," in Multilateral Meeting-1 Penyusunan RKP 2017. Kementerian Perencanaan Pembangunan Nasional, Badan Perencanaan Nasional, p. 46.

Badan Pusat Statistik (2017) Statistik Indonesia 2017 (Statical yearbook of Indonesia). Badan Pusat Statistik. Available at: https://www.bps.go.id/publication/2017/07/2 6/b598fa587f5112432533a656/statistikindonesia-2017.html.

Damuri, Y. R., Christian, D. and Atje, R. (2015) Kawasan ekonomi khusus dan strategis Indonesia: Tinjauan atas peluang dan permasalahan. Jakarta: Centre for Strategic and International Studies. Available at: https://media.neliti.com/media/publications/2 26-ID-kawasan-ekonomi-khusus-dan-strategisdi-indonesia-tinjauan-atas-peluang-danperm.pdf.

Destaningtyas, V. (2010) Kawasan ekonomi khusus di Indonesia sebagai upaya peningkatan penanaman modal dan daya saing Internasional. Universitas Indonesia. Available at: $\quad$ http://lib.ui.ac.id/file?file $=$ digital/20168/20200289-S25057-Valenshia

Destaningtyas.pdf.

Direktorat Jenderal Mineral dan Batubara (2017) Laporan kinerja 2016. Jakarta. Available at: https://www.minerba.esdm.go.id/library/publi sh/LAKIN MINERBA 2016.pdf.

Erlina (2009) "Analisis kinerja perusahaan dengan metode balanced score card (BSC) dan SWOT," Jurnal Penelitian Ilmu Teknik, 9(1), pp. 48-57. Available at: http://eprints.upnjatim.ac.id/3165/1/6._Jurnal_ Erlina.pdf.

Gunawan, I. and Maryoni, H. S. (2017) "Dinamika penetapan kawasan ekonomi khusus dalam memengaruhi kebijakan wilayah desa," Sungkai-Jurnal Penelitian Pertanian, 5(1), pp. 69-95. Available at: http://ejournal.upp.ac.id/index.php/sungkai/article/vi ew/1210. 
Haryadi, H. (2016) "Analisis dampak pembangunan smelter nikel terhadap perekonomian daerah di Provinsi Sulawesi Tenggara," Buletin Sumber Daya Geologi, 11(1), pp. 25-39. Available at: http://buletinsdg.geologi.esdm.go.id/index.ph p/bsdg/article/view/BSDG_VOL_11_NO_1_2 016_3.

Haryadi, H. (2017) "Analisis neraca sumber daya pasir besi dan bijih nikel Indonesia," Jurnal Teknologi Mineral dan Batubara, 13(2), pp. 153-169. 10.30556/jtmb.Vol13.No2.2017.171.

Munawaroh, R. R. S. and Suryana, L. (2013) "Analisis SWOT sebagai dasar oenetapan strategi pemasaran pada perusahaan Jamu Cuk Sirih di Banjarmasin," Jurnal Manajemen dan Akuntansi, 13(2), pp. 31-38. Available at: $\quad$ http://journal.stiei-kayutangibjm.ac.id/index.php/jv112/article/view/164.

Permana, D. (2010) “Dampak penerapan UndangUndang No. 4 Tahun 2009 tentang pengembangan usaha pertambangan mineral dan batubara," Jurnal Teknologi Mineral dan Batubara, 6(4), pp. 165-173.

Pramoda, R. and Apriliani, T. (2016) "Kebijakan Penetapan Bitung Sebagai Kawasan Ekonomi Khusus (KEK)," Jurnal Borneo Administrator, 12(2), pp. 149-169. doi: 10.24258/jba.v12i2.238.

Purba, H. (2006) "Kawasan ekonomi khusus (KEK) fenomena global, suatu kajian aspek hukum," Jurnal Equality, 11(2), pp. 123-130. Available at:

https://www.researchgate.net/publication/439 01858_Kawasan_Ekonomi_Khusus_KEK_Feno mena_Global_Süatu_Kajian__Aspek_Hukum.

Pusat Sumber Daya Geologi (2016) Laporan akhir pemutakhiran data dan neraca sumber daya mineral. Bandung.

Rahayu, D. T. and Retnani, E. D. (2016) "Penerapan analisis SWOT dalam perumusan strategi bersaing pada Eddy Jaya Photo," JIRA, 5(2), pp. 1-16. Available at: https://ejournal.stiesia.ac.id/jira/article/view/1 638.

Rangkuti, F. (2006) "Reorientasi konsep perencanaan strategis untuk menghadapi abad 21," in Analisis SWOT Teknik Membedah Kasus Bisnis. Jakarta: PT. Gramedia Pustaka Utama, p. 200.

Rohman, M. F. (2015) Teknik analisis manajemen SWOT: Untuk menyusun kertas kerja proyek diklat pimpinan (KKP DIKLATPIM) \& rencana strategis (RENSTRA). Mobicons.

Sekretariat Dewan Nasional Kawasan Ekonomi Khusus (2013) "Prospek pengembangan kawasan ekonomi khusus (KEK) di Sulawesi Selatan." Kementerian Koordinator Bidang Perekonomian, Sekretariat Dewan Nasional Kawasan Ekonomi Khusus, p. 28.

Sihaloho, T. and Muna, N. (2010) "Kajian dampak ekonomi pembentukan kawasan ekonomi khusus," Buletin Ilmiah Litbang Perdagangan, 4(1), pp. 75-101. Available at: http://jurnal.kemendag.go.id/index.php/bilp/a rticle/view/150.

Sudirman (2011) "Analisis SWOT untuk menentukan strategi pemasaran pada Harian Fajar di Makasar," Jurnal Manajemen dan Akuntansi, 12(2), pp. 185-188. Available at: http://journal.stiei-kayutangi-

bjm.ac.id/index.php/jv112/article/view/47.

Suhandi, Susanto, H. and Hutamadi, R. (2011) "Penelitian bahan galian lain dan mineral ikutan pada wilayah pertambangan Kabupaten Konawe," in Prosiding Hasil Kegiatan Pusat Sumber Daya Geologi Tahun 2011. Bandung: Pusat Sumber Daya Geologi, p. II.9. Available at: http://psdg.geologi.esdm.go.id/prosiding_201 2/Buku 2 Mineral/09. Prosiding Konawe.pdf.

Sumiati (2015) "Menentukan strategi pemasaran melalui analisis SWOT pada perusahaan air mineral di Surabaya," Jurnal Media Mahardhika, 13(2), pp. 192-206.

Syahza, A. and Suarman, S. (2013) "Strategi pengembangan daerah tertinggal dalam upaya percepatan pembangunan ekonomi pedesaan," Jurnal Ekonomi Pembangunan: Kajian Masalah Ekonomi dan Pembangunan, 14(1), p. 126. doi: 10.23917/jep.v14i1.166.

Tamara, A. (2016) "Implementasi analisis SWOT dalam strategi pemasaran produk mandiri tabungan," Jurnal Riset Bisnis dan Manajemen, 4(3), pp. 395-406. Available at: https://ejournal.unsrat.ac.id/index.php/jrbm/ar ticle/view/12751.

Wahyuni, S. and Wahyuningsih (2016) Pedoman praktis strategi pengembangan kawasan ekonomi khusus. Jakarta: Penerbit Salemba Empat. Available at: http://stafsite.untad.ac.id/upload/jurnal/44Wa hyuningsih-Buku Strategi Pengembangan KEK.pdf. 
Analisis SWOT Pengembangan Ekonomi Khusus (KEK) Industri Nikel ... Meitha Suciyanti dan Harta Haryadi

Yunianto, B. (2014) "Analisis dampak penerapan kebijakan nilai tambah mineral Indonesia terhadap ekspor dan tenaga kerja," Jurnal
Teknologi Mineral dan Batubara, 10(3), pp. 127-141. 
